\title{
GEOQUÍMICA DE ANFIBOLITOS DA SEQÜÊNCIA DE JUSCELÂNDIA, GOIÁS: IMPLICAÇÕES GEOTECTÔNICAS
}

\author{
RAUL M. KUYUMJIAN* \& JOSÉ C.M. DANNI*
}

\begin{abstract}
GEOCHEMISTRY OF THE JUSCELÂNDIA SEQUENCE AMPHIBOLITES, GOIÁS: GEOTECTONIC IMPLICATIONS. Trace and rare earth element composition of the Proterozoic amphibolites from the lower unit of the Juscelândia volcano-sedimentary sequence, State of Goiás, Brazil, suggests a non-subductipn, tholeiitic original nature for these rocks, probably of back-arc type tectonic setting. A more detailled reconstruction of the geotectonic evolution of the sequence, requires a reappraisal of its larger geological environment, particularly
\end{abstract} involving the critical area of the Barro Alto complex.

Keywords: Amphibolites, geochemistry, Juscelândia, Goiás, Brazil.

RESUMO Neste estudo, são apresentados novos resultados analíticos de elementos-traço incompatíveis dos anfibolitos da porção inferior da Seqüência vulcanossedimentar de Juscelândia. Tais resultados evidenciam que os anfibolitos apresentam afinidade química com basaltos toleíticos de bacia marginal. A identificação desse ambiente para o posicionamento geotectônico dos anfibolitos estudados sugere um modelo para a Seqüência de Juscelândia

e suas correlatas (Seqüências de Indaianópolis e Palmeirópolis) a partir da evolução de bacia do tipo intra-arc

Palavras-chaves: Anfibolitos, geoquímica, Juscelândia, Goiás, Brasil.

INTRODUÇÃO No flanco ocidental dos Complexos de Barro Alto, Niquelândia e Canabrava, abrangendo uma extensão de $350 \mathrm{~km}$, ocorrem três importantes seqüências vulcanossedimentares conhecidas, respectivamente, sob a denominação de Juscelândia, Indaianópolis e Palmeirópolis.

Na região de Niquelândia, Darmi \& Leonardos (1980) propuseram uma evolução continua para a seqüência gabro-anortosítica acamadada da Serra dos Borges e a dos metabasaltos de Indaianópolis, em que a primeira representaria um complexo diferenciado, gerado em câmara magmática rasa em ambiente extensional do tipo ridge, sotoposta a uma carapaça basáltica, a qual configuraria parte de uma crosta oceânica.

Os resultados das pesquisas empreendidas no Complexo de Barro Alto vieram confirmar esse modelo geológico (Fuck et al 1981) e evidenciar a estreita correspondência estratigráfica e de conteúdo litológico entre as seqüências de Indaianópolis e de Juscelândia (Fig. 1).

Em 1984, Danni \& Kuyumjian desenvolveram um estudo sobre a química dos anfibolitos da unidade inferior da Seqüência de Juscelândia e demonstraram que eles têm composições de basaltos toleíticos, com características geoquímicas comparáveis às dos basaltos de cadeias rnesooceânicas.

Estudos posteriores sobre as Seqüências de Palmeirópolis e Indaianópolis (Araújo 1986, Brod 1988) demonstraram a ocorrência de séries vulcânicas de natureza cálcio-alcalina e alcalina nas porções superiores destas seqüências, compatíveis com evolução a partir de ambientes do tipo arco-de-ilha.

Neste estudo, são apresentados e discutidos novos dados geoquímicos de elementos-traço mais recentes sobre os anfibolitos da porção inferior da Seqüência de Juscelândia, o que permitiu melhor caracterização do provável ambiente geotectônico em que os mesmos se formaram. As amostras analisadas foram escolhidas dentre aquelas utilizadas em trabalho anteriormente efetuado pelos autores (Danni \& Kuyumjian 1984). O número reduzido de amostras considerado neste trabalho deve-se ao fato de que as análises químicas das mesmas foram feitas durante a pesquisa para doutorado de um dos autores
(Kuyumjian), sobre assunto distinto ao do enfocado neste trabalho. Naquela situação, não foi possível efetuar análises químicas de um número maior de amostras não relacionadas ao assunto de tese desenvolvido. No entanto, a dificuldade que se tem atualmente no Brasil em se dosar elementos-traço, tais como tântalo, háfnio, tório, nióbio e terras raras, e a importância destes elementos no estudo das rochas metavulcânicas, justificam a publicação deste trabalho.

PETROGRAFIA DOS ANFIBOLITOS A estratigrafia da Seqüência vulcano-sedimentar de Juscelândia compreende três unidades principais (Fig. 1). A inferior é constituída essencialmente de anfibolitos finos, com raras intercalações de metacherts e micaxistos. Na unidade intermediária, predominam biotita e homblenda gnaisses, com intercalações de anfibolito uno, metachert, formação ferrífera e micaxistos. A unidade superior é constituída essencialmente de metassedimentos e, subordinadamente, anfibolito fino, biotita gnaisse, metachert e formação ferrífera. O metamorfismo regional transiciona da fácies anfibolito (base da seqüência) para a fácies xisto verde (topo da seqüência)

Os anfibolitos basais, tipo litológico enfocado neste artigo, são finos, bastante foliados e mostram textura predominantemente nematoblástica. São constituídos essencialmente por homblenda verde ( 30 a $45 \%$ do volume), plagioclásio de composição andesina (An 32\%), granada almanctína, titanita, epídoto, magnetita, ilmenita e, ocasionalmente, pinta e cálcio-pirita. Os tipos petrográficos mais freqüentes constituem epídoto anfibolitos e granada-epídoto anfibolitos. A presença de textura subofítica reliquiar, de restos de clkiopiroxênio (diopsídio-augita) ígneo, e de micrólitos de plagioclásio são aspectos indicativos de derivação ígnea, a partir de protólitos do tipo basalto.

ANÁLISES QUÍMICAS Apesar das determinações analíticas deste estudo limitarem-se a apenas cinco amostras (Tab. 1), elas correspondem a exemplares representativos dos anfibolitos basais, e os dados obtidos são consistentes e coerentes entre si. 


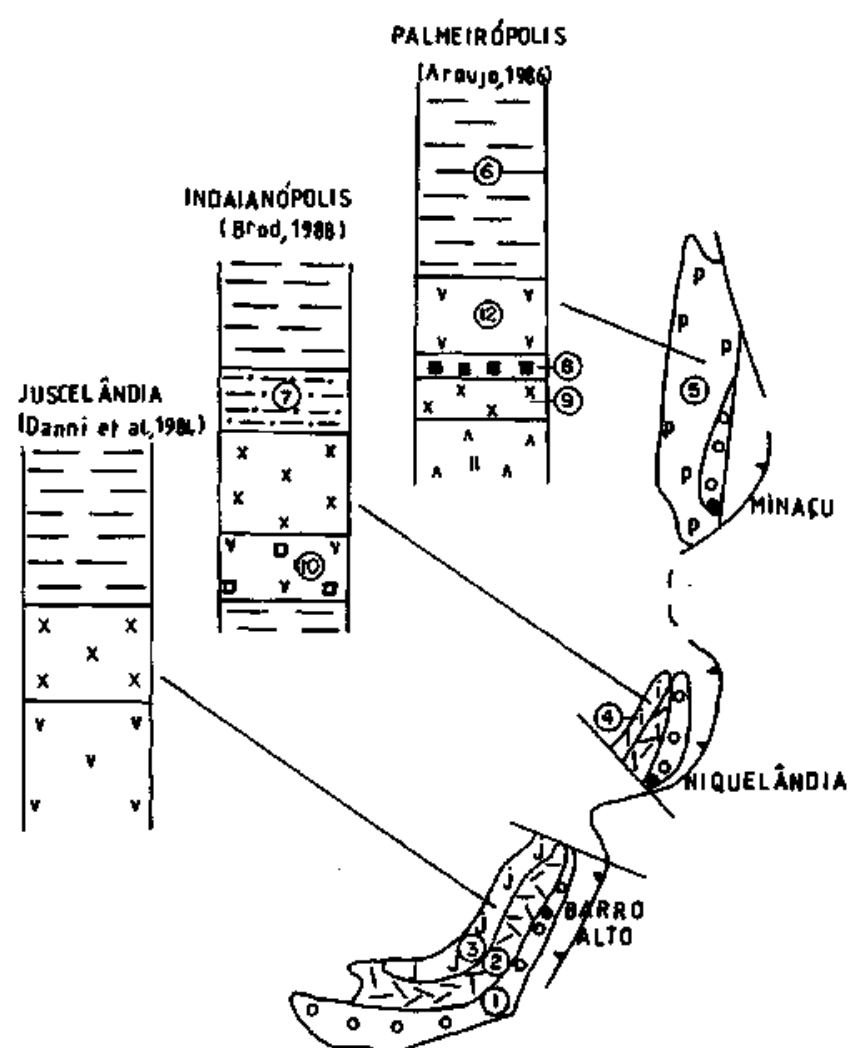

Figura 1 - Colunas estratigráficas das Seqüências de Juscelândia, Indaianópolis e Palmeirópolis, e localização das mesmas nos Maciços de Barro Alto, Niquelândia e Canabrava, respectivamente. 1. Granulitos; 2. intrusões gabro-anortositicas; 3. Seqüência de Juscelândia; 4. Seqüência de Indaianópolis; 5. Seqüência de Palmeirópolis; 6. metapelitos e metapsamitos; 7. metapelitos e sedimentos químicos; 8 . metagrauvacas; 9. rochas metavulcânicas ácidas e intermediárias; 10. rochas metapiroclásticas básicas; 11. anfibolitos gabróicos; 12. anfibolitos finos

Figure 1 - Stratigraphic column of the Juscelândia, Indaianópolis and Palmeirópolis Sequences, and their locations in relation to the Barro Alto, Niquelândia e Canabrava respective Complexes. 1. Granulites; 2. anorthositic gabbroic intrusions; 3. Juscelândia Sequence; 4. Indaianópolis Sequence; 5. Palmeirópolis Sequence; 6. metapsamites and metapelites; 7. metapelites and chemical sediments; 8 . metagreywackes; 9 . acid and intermediate metavolcanics; 10. basic metapyroclastics; 11. gabbroic amphibolites; 12. fine grained amphibolites

As análises químicas foram efetuadas nos laboratórios do Departament of Geology, Imperial College, Londres, Inglaterra. Os elementos terras raras foram dosados por meio de ativação neutrônica, enquanto $\mathrm{Zr}, \mathrm{Y}$, Ta, Th, Hf e $\mathrm{Nb}$ foram dosados por fluorescência de raios X. Os teores de $\mathrm{Ba}$ e Ni utilizados neste estudo são aqueles obtidos previamente por Danni \& Kuyumjian (1984). Os valores de TiOi são mais elevados que aqueles obtidos anteriormente por Danni e Kuyumjian (1984), e devem ser mais corretos, pois anfibolitos pertencentes a seqüências correlatas à de Juscelândia (Palmeirópolis e Indaianópolis) e aqueles das porções superiores da Seqüência de Juscelândia apresentam valores de $\mathrm{TiO}_{2}$ geralmente acima de a $1,50 \%$.

PRINCIPAIS DADOS OBTIDOS No estudo efetuado por Danni \& Kuyumjian (1984) foram utilizados diagramas discriminantes do tipo FeO-MgO- $\mathrm{Al}_{2} \mathrm{O}_{3}$, TiCh-PaOs e $\mathrm{Ti} / \mathrm{Cr}-\mathrm{Ni}$. Estudos efetuados por Kuyumjian (1991a, b), sobre mobilidade de elementos químicos em rochas anfibolíticas
Tabela 1 - Teores de elementos-traçò e terras raras em anfibolitos da porção inferior da Seqüência de Juscelândia, Os resultados analíticos estão expressos em ppm. $\mathrm{TiO}_{2}$ em $\%$ Table 1 - Trace element and rare earth concentrations in amphibolites from the lower portion of the Juscelândia sequence. Analytical results expressed in ppm. $\mathrm{TiO}_{2}$ in $\%$

\begin{tabular}{|c|c|c|c|c|c|c|c|c|c|c|c|}
\hline \multicolumn{12}{|c|}{ ELEMENTOS-TRAÇO } \\
\hline & Ba & $\mathbf{R} \mathbf{b}$ & Sr & $\bar{Y}$ & $\overline{\mathbf{Z}} \mathbf{r}$ & $\mathbf{N i}$ & $\overline{\mathbf{N} b}$ & $\mathbf{T a}$ & $\bar{H} \bar{f}$ & Th & $\mathrm{TiO}_{2}$ \\
\hline $\mathbf{I}$ & 30 & 5 & 129 & 36 & 114 & 85 & 5,9 & 0,40 & $\mathbf{3 , 4 1}$ & 0,40 & 1,90 \\
\hline 3 & 30 & $\mathbf{5}$ & 104 & 25 & 76 & 70 & 4,8 & 0,37 & 2,46 & 0,39 & 1,44 \\
\hline 6 & 20 & 3 & 108 & 25 & 70 & 100 & 5,1 & 0,35 & 2,30 & 0,20 & 1,25 \\
\hline 7 & 30 & 8 & 87 & 16 & 41 & 105 & 2,2 & 0,15 & 1,32 & 0,60 & 0,81 \\
\hline 10 & 30 & 3 & 94 & 24 & 78 & 80 & 6,2 & 0,57 & 2,83 & 0,37 & 1,79 \\
\hline \multicolumn{12}{|c|}{ ELEMENTOS TERRAS RARAS } \\
\hline & & $\mathrm{Ce}$ & Nd & & $\mathbf{S m}$ & Eu & & Tb & $\mathbf{Y b}$ & & Lu \\
\hline 1 & & 21,62 & 12,60 & & 3,20 & 1,79 & & 1,12 & 4,0 & & 0,37 \\
\hline 3 & & 19,29 & 11,15 & & 3,31 & 1,41 & & 0,88 & 3,2 & & 0,30 \\
\hline 6 & & 20,19 & 10,00 & & 3,73 & 1,38 & & 0,86 & 3,0 & & 0,26 \\
\hline 7 & & 10,72 & 4,66 & & 1,74 & 0,85 & & 0,50 & 2,1 & & 0,24 \\
\hline 10 & & 24,62 & 17,3 & & 4,58 & 1,64 & & 1,04 & 3,6 & & 0,35 \\
\hline
\end{tabular}

das regiões de Chapada e de Crixás, Goiás, mostram que, ao contrário de $\mathrm{Fe}$ e $\mathrm{Mg}$, os elementos $\mathrm{Ti}$, Ta, Th, Hf, $\mathrm{Nb}, \mathrm{Y}, \mathrm{Zr}$ e terras raras pesados, os quais serão considerados neste estudo, são pouco afetados por processos metamórficos da fácies anfibolito.

A discriminação entre anf ibolitos oito e paraderivados tem sido testada por vários critérios. Dentre os métodos de discriminação da procedência a partir de rochas vulcânicas, o diagrama $\mathrm{Zr} / \mathrm{TiOz}-\mathrm{Ni}$ de Winchester et al. (1980) tem sido freqüentemente empregado. Considerando esses elementos, fica evidente a origem ígnea a partir de basaltos (Fig. 2).

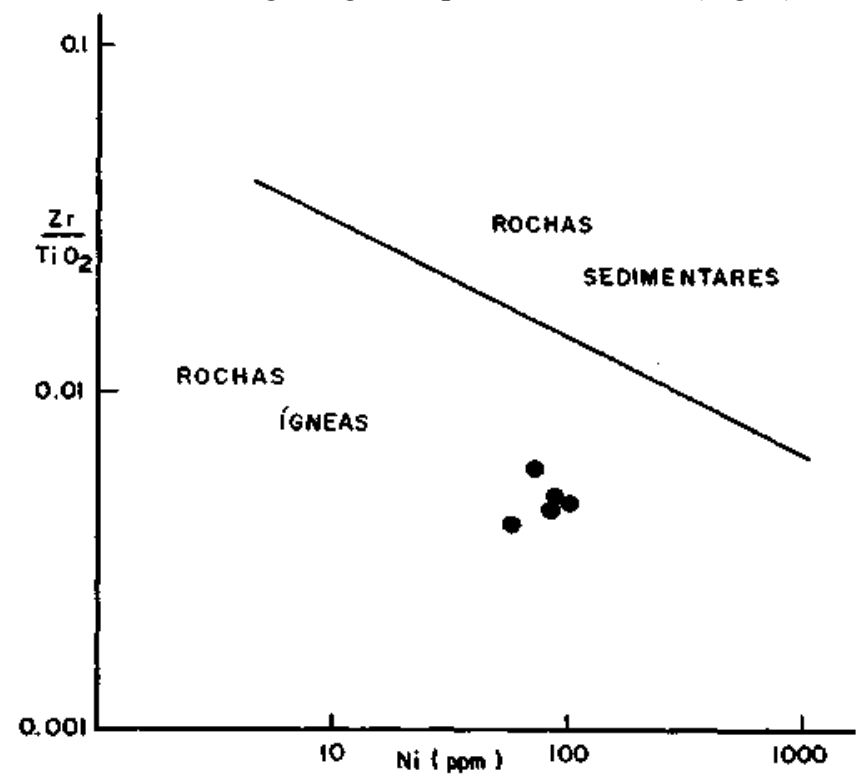

Figura 2 - Diagrama $\mathrm{Zr} / \mathrm{TiO}_{2}-\mathrm{Ni}$ (Winchester et al. 1980). Caracterização da origem ígnea dos anfibolitos da porção inferior da Seqüencia de Juscelândia

Figure 2 - $\mathrm{Zr} / \mathrm{TiO}_{2} \mathrm{Ni}$ diagram (Winchester et al. 1980). Characterization of igneous origin to the amphibolites of lower portion of the Juscelândia sequence

A validade da utilização da co-variancia entre razões de elementos imóveis para classificar rochas metavulcânicas foi demonstrada por Floyd \& Winchester (1978). No diagrama $\mathrm{Zr} / \mathrm{TiO}_{2}-\mathrm{Nb} / \mathrm{Y}$, a razão $\mathrm{Zr} / \mathrm{TiO}_{2}$ constitui um índice de dife- 
renciação, enquanto a razão $\mathrm{Nb} / \mathrm{Y}$ é um indicador de alcalinidade das rochas. Com base nesse diagrama (Fig. 3), os anfibolitos basais da Seqüência de Juscelândia são classificados como basaltos subalcalinos.

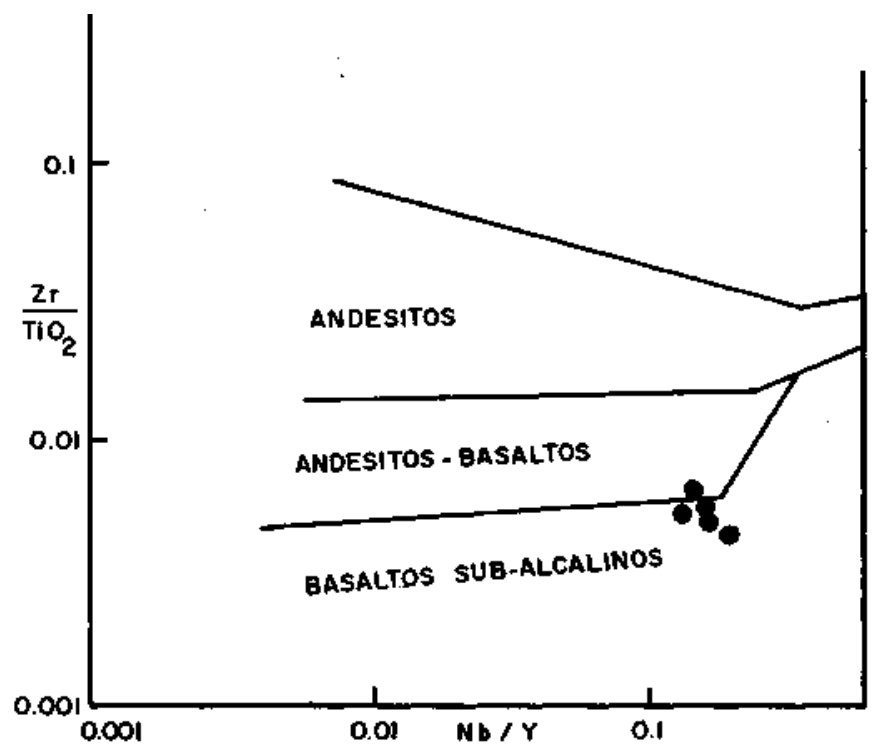

Figura 3-Diagrama $\mathrm{Z}_{\mathrm{H}} / \mathrm{TO}_{2}-\mathrm{Nb} / \mathrm{Y}$ (Floyd \& Winchester 1978). Classificação dos anfibolitos da porçấo inferior da Sequéncia de Juscelandia

Figure 3 - Zr/ThO,-Nb/Y diagram (Floyd \& Winchester 1978). Classification of the amphibolites from the lower portion of the Juscelindia Sequence

A utilização de parâmetros químicos, mesmo considerando elementos imóveis, para a identificação de ambientes geotectônicos geradores de rochas vulcânicas envolvidas em eventos tectono-metamórfícos tem sido freqüentemente criticada. Tal crítica deve-se ao fato de que tais discriminantes foram estabelecidos a partir de composições químicas de rochas recentes não metamorfisadas. Porém, a aplicação dos mesmos tem-se mostrado válida, mesmo para rochas antigas, principalmente quando se consideram elementos imóveis (Beswich \& Soucie 1978). A razoável consistência das indicações fornecidas pelos diagramas utilizados neste estudo justifica considerá-las significativas

No diagrama Ti-Zr de Pearce \& Carm (1973), utilizado para distinguir basaltps gerados em ambiente de arco de ilhas, de back-arc, de cadeia meso-oceânica e de interior de placas, os anfibolitos basais ocupam o campo de cadeia mesoceânica (Fig. 4). No entanto, estas composições situam-se também em áreas de superposição dos campos de arco-de-ilhas, e interior de placas.

Wood et al. (1979) propuseram o diagrama triangular Th-Hf-Ta como discriminante tectono-magmático para rochas ígneas de composição básica a intermediária. Neste diagrama (Fig. 5), os anfibolitos basais situam-se nitidamente no campo dos basaltos de cadeia mesoceânica. $\mathrm{O}$ diagrama $\mathrm{Th} / \mathrm{Yb}$ $\mathrm{Ta} / \mathrm{Yb}$, de Pearce (1982), confirma essa afinidade (Fig. 6), enquanto no diagrama Nb-Zr-Y, de Meschede (1986) (Fig. 7), uma amostra situa-se no campo dos basaltos de arcos-de-ilhas e as demais, no campo onde se superpõem basaltos de arcode-ilha e de cadeia mesoceânica.

A concentração dos elementos terras raras dos anfibolitos basais, quando normalizados a condrito, apresenta uma distribuição segundo padrões planos (10 vezes condrito). Tais padrões coincidem com aqueles típicos de basaltos do arcosde-ilhas imaturos e de cadeias mesoceânicas (Fig. 8).

A representação de elementos-traço, ordenados segundo incompatibilidade decrescente em gráficos do tipo spidergram

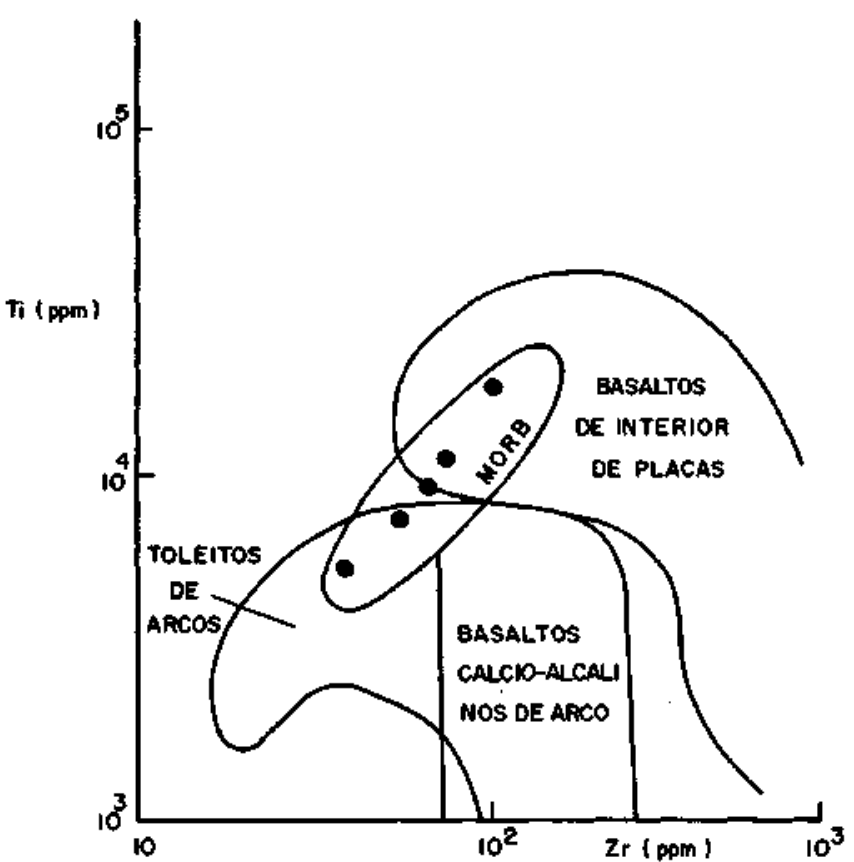

Figura 4 - Diagrama Ti-Zr (Pearce \& Cann 1973). Discriminação do ambiente geotectônico de posicionamento dos anfibolitos da porção inferior da Seqüência de Juscelândia Figure 4 - Tí-Zr diagram (Pearce \& Cann 1973). Discrimination of the geotectonic setting for the emplacement of the amphibolites from the lower portion of the Juscelândia Sequence

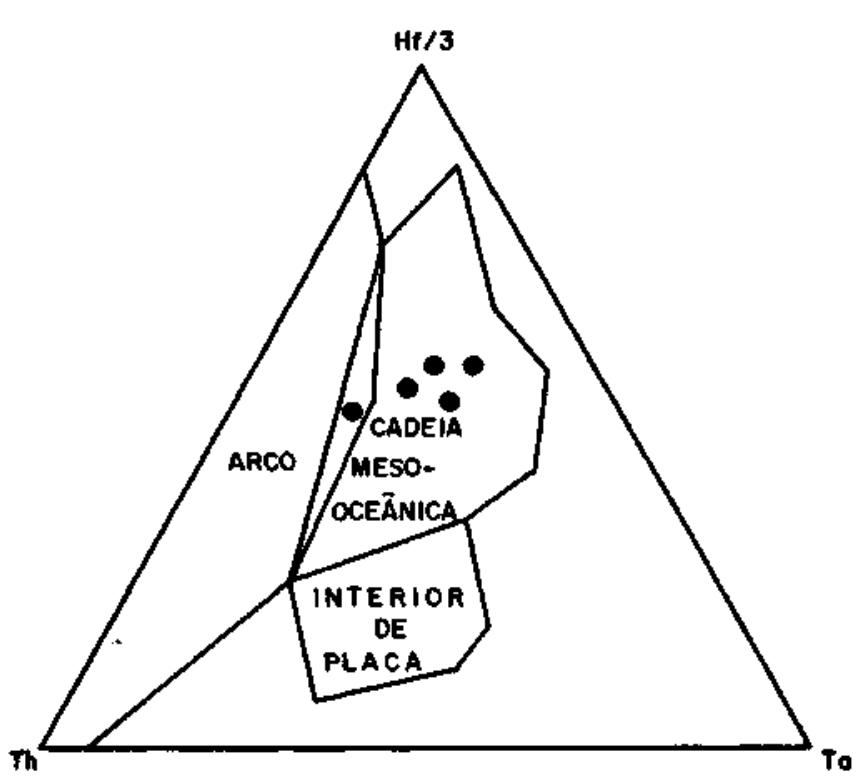

Figura 5 - Diagrama Th-Hf-Ta (Wood et al. 7979). Discriminação tectono-magmática dos anfibolitos da porção inferior da Seqüência de Juscelândia

Figure 5 - Th-Hf-Ta diagram (Wood et al. 1979). Tectono-magmatic discrimination of the amphibolites from the lower portion of the Juscelândia Sequence

(Thompson et al 1984), permite caracterizar e comparar padrões de variação de elementos incompatíveis e possibilita uma melhor identificação de ambientes tectono-magmáticos. Na figura 9, os padrões obtidos para os anfibolitos estudados, normalizados a basaltos de cadeia mesoceânica (MORE), mostram nítida afinidade química com os basaltos de backarc. Mais especificamente, eles não mostram as anomalias 


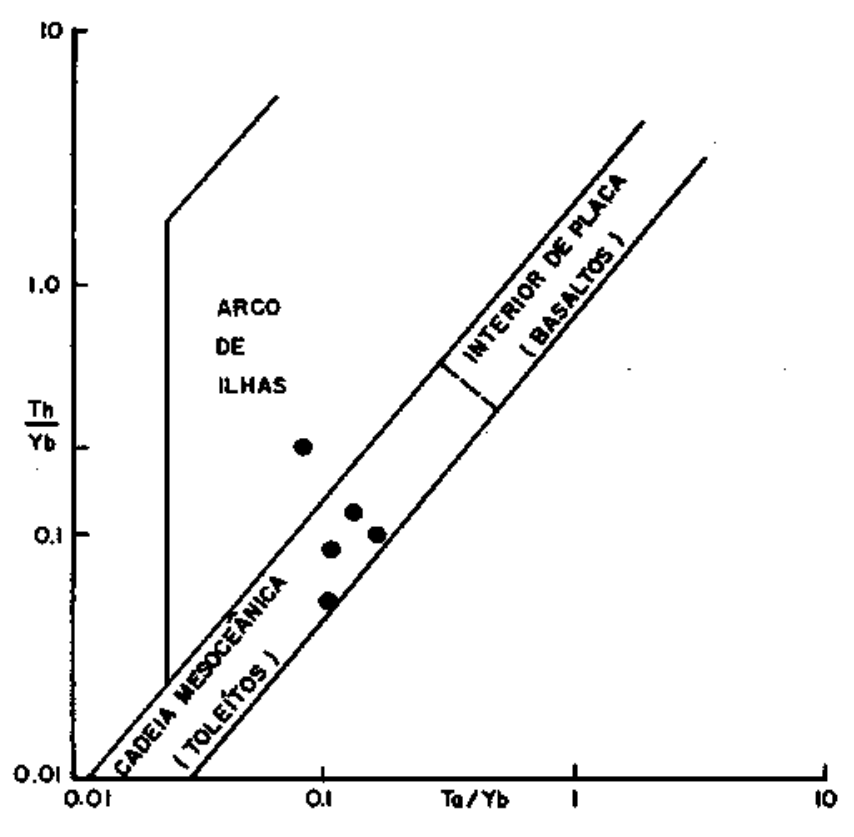

Figura 6 - Diagrama Th/Yb-Ta/Yb (Pèarce 1982). Discriminação de ambiente geotectônico do posicionamento dos anfibolitos da porção basal da Seqüência de Juscelândia Figure $6-\mathrm{Th} / \mathrm{Yb}-\mathrm{Ta} / \mathrm{Yb}$ diagram (Pearce 1982). Discrimination of the geotectonic setting for the emplacement of the amphibolites from the lower portion of the Juscelândia Sequence

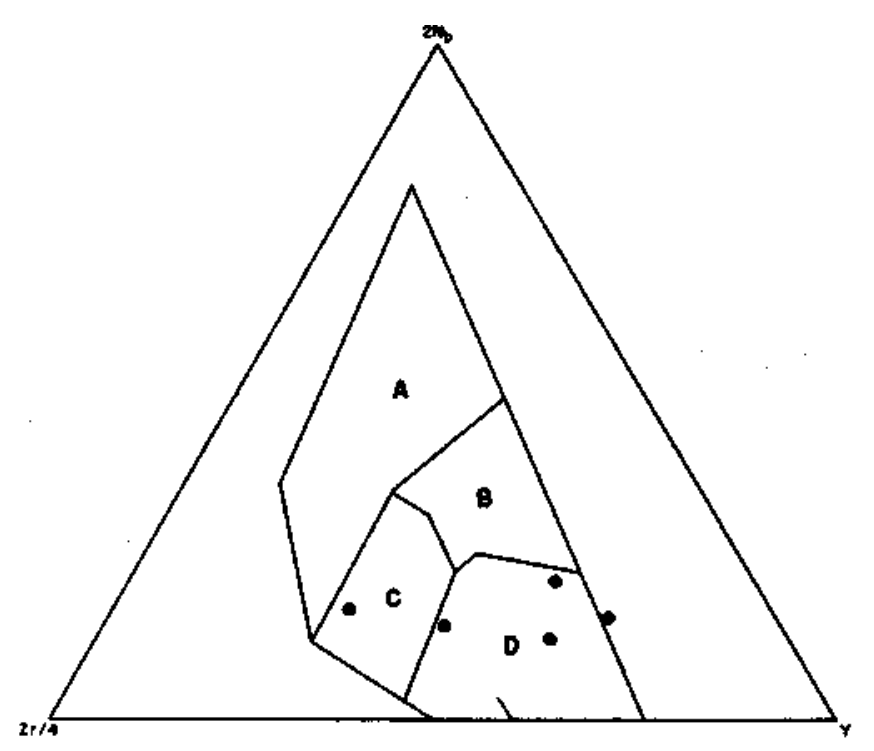

Figura 7 - Diagrama Nb-Zr-Y (Meschede 1986). Discriminação de ambiente geotectônico de posicionamento dos anfibolitos da porção basal da Seqüencia de Juscelândia. A. Basaltos de intraplaca; B. Basalto MORB-P;D. Basalto $M O R B-N ; \quad C+D$. Basalto de arco vulcânico Figure 7 - Nb-Zr-Y diagram (Meschede 1986). Discrimination of the geotectonic setting for the emplacement of the amphibolites from the lower portion of the Juscelândia Sequence. A. Within-plate basalts; B. P-type MORE; D. N-type MORE; C+D. Volcanic-arc basalts

negativas de $\mathrm{Nb}$, que são diagnosticas e características dos basaltos gerados em arco-de-ilhas.

Myers \& Breitkopf (1989) sugerem a utilização de spidergrams de razões normalizadas aos valores das razões corres-

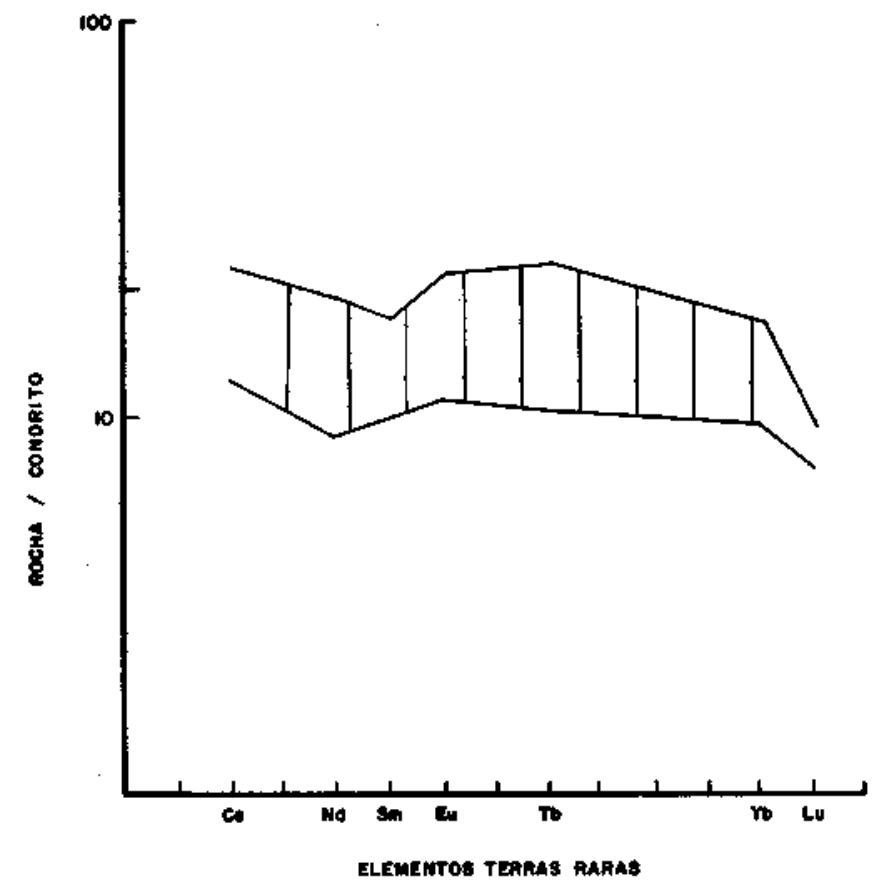

Figura 8 - Envelope dos padrões de elementos terras raras dos anfibolitos da porção basal da Seqüencia de Juscelândia. Os valores de condrito utilizados para a normalização são aqueles indicados por Thompson et al. 1984

Figure 8 - Envelope for the raie earth element patterns for the amphibolites from the lower portion of the Juscelândia Sequence. Values for normalization are those indicated by Thompson et al. 1984

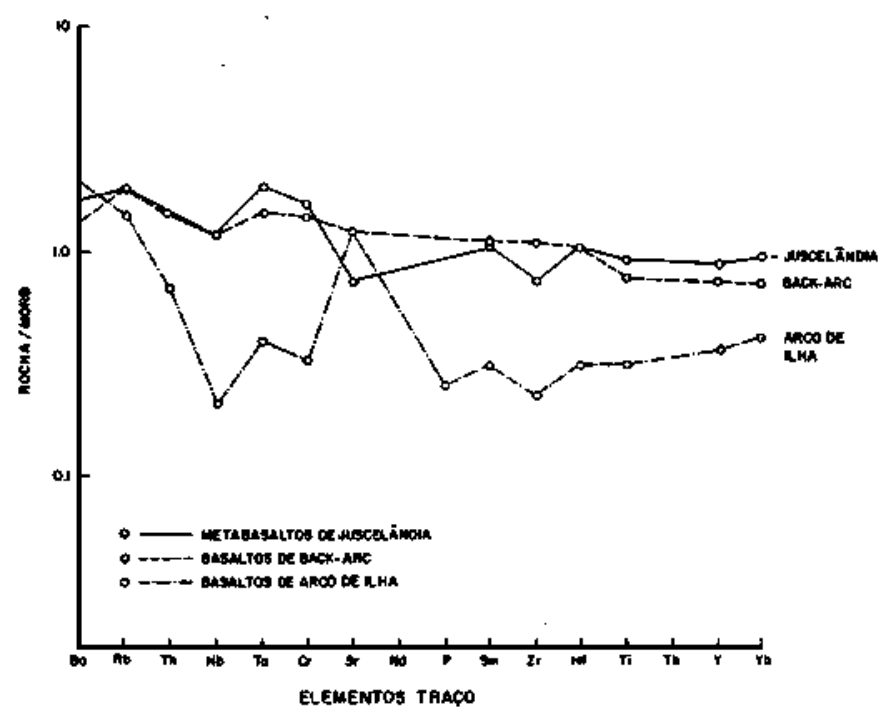

Figura 9 - Comparação entre os padrões de elementos incompativeis normalizados com basalto de cadeia mesoceânica, de anfibolitos de Juscelândia e de basaltos de bacia marginal e de arco-de-ilha. Padrões de basaltos de bacia marginal e de arco-de-ilha obtidos a partir de dados analiticos fornecidos por Pèarce (1982) e Sounders \& Tarney (1979). Valores de basaltos de cadeia mesoceânica para normalização são aqueles indicados por Pearce (1982) Figure 9 - Comparison between incompatible element patterns normalized to MORB from Juscelândia amphibolites, and marginal basin and island-arc basalts. Patterns for the marginal basin and island-arc basalts were obtained from analytical data indicated by Pearce (1982) and Saunders \& Tarney (1979). MORB values for normalization are those indicated by Pearce (1982)

pendentes do manto primordial, como sendo a melhor maneira para identificar variações na composição de elementos-traço 
incompatíveis que permitam distinguir diferentes tipos de manto suboceânico. O nióbio foi escolhido para ser o elemento divisor daquelas razões, por se tratar do elemento mais incompatível dentre aqueles considerados para a elaboração de spidergram, tal como sugerido por esses autores. A utilização desse diagrama (Fig. 10) permitiu confirmar a semelhança composicional entre os anfibolitos da porção inferior da Seqüência de Juscelândia e os basaltos de bacia marginal tipo back-arc.

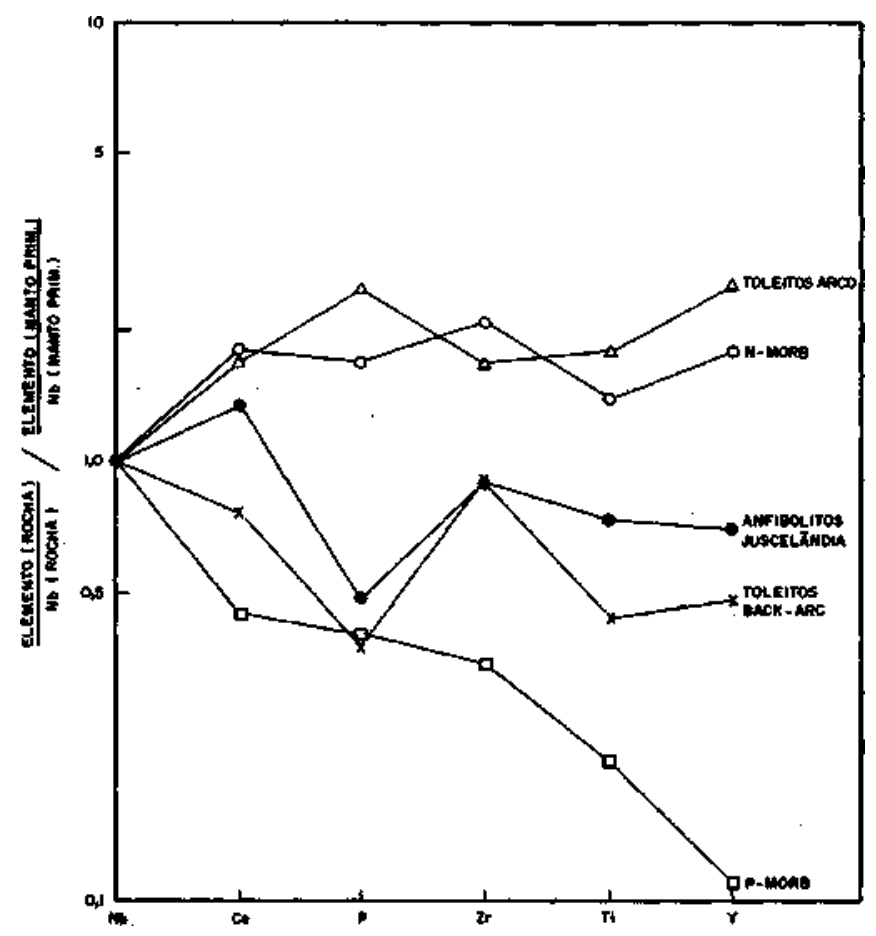

Figura 10- Comparação entre os padrões de distribuição de elementos-traço incompativeis normalizados com nióbio, de anfibolitos da Seqüencia de Juscelândia, e de basaltos de cadeia mesoceânica, arcos-de-ilhas e bacia marginal tipo back-arc. Os padrões de basaltos N-MORB e P-MORB, toleitos de arco-de-ilha e de bacia marginal foram obtidos de Myers \& Breitkopf (1989). Os valores de Manto Primordial utilizados para a normalização são aqueles indicados por Wood (1979)

Figure 10 - Comparison between incompatible element patterns normalized to niobium from Juscelândia amphibolites, and MORB, marginal basin and island arc basalts. Patterns for N-MORB and P-MORB type, and toleiites from marginal basin and island arc are from Myers \& Breitkopf (1989). Primordial Mantle values for normalization are those indicated by Wood (1979)

CONSIDERAÇÕES FINAIS Embora os metabasaltos finos da porção basal da Seqüência de Juscelândia estejam metamorficamente recristalizados, a sua composição química, de elementos menores e traço, provavelmente os menos redistribuídos, confirma as conclusões anteriormente obtidas por Danni \& Kuyumjian (1984), de que tais anfibolitos são de origem ígnea e que suas rochas precursoras constituiram basaltos toleíticos subalcalinos. Aplicando-se a estas rochas metamórfícas as relações estabelecidas entre as composições químicas de rochas vulcânicas e os ambientes geotectônicos geradores, os diagramas discriminantes mostram que os protólitos desses anfibolitos foram posicionados em ambiente de cadeia mesoceânica. Rochas basáltícas de cadeia mesoceânica e de back-arc mostram composições químicas muito semelhantes entre si e, na maior parte das vezes, impossíveis de serem distinguidas umas das outras. No entanto, os padrões de elementos-traço obtidos revelam a identificação química dos anfibolitos basais com os basaltos gerados em ambientes de expansão de fundo oceânico, do tipo bacia marginal.

Nesse modelo (Fig. 11), os anfibolitos da Seqüência de Juscelândia representariam as rochas vulcânicas basálticas formadas em ambientes de dorsais de bacias intra-arco de ilhas. As séries vulcânicas dos sistemas de arco estariam edificadas acima e lateralmente, enquanto as pilhas de cumulados gabro-anortosíticos (e.g. Seqüência Serra da Malacacheta) representariam corpos gerados nas raízes dos arcos, a partir de magmas toléticos ricos em alumínio. Os conjuntos de gabro-noritos, piroxenitos e peridotitos, por sua vez, representariam as raízes de edifícios ofiolíticos (transição entre manto-crosta oceânica).

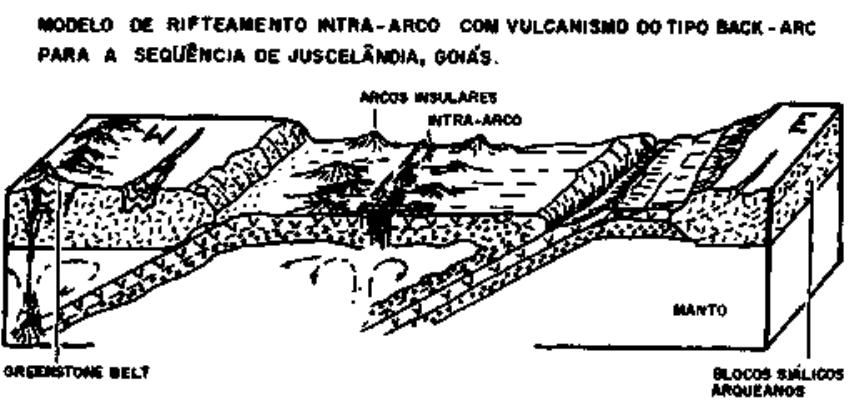

COLISÃo DE GLOCOS CONTIMENTAIS : FOAMACÃ̃o DE UMA SUTURA

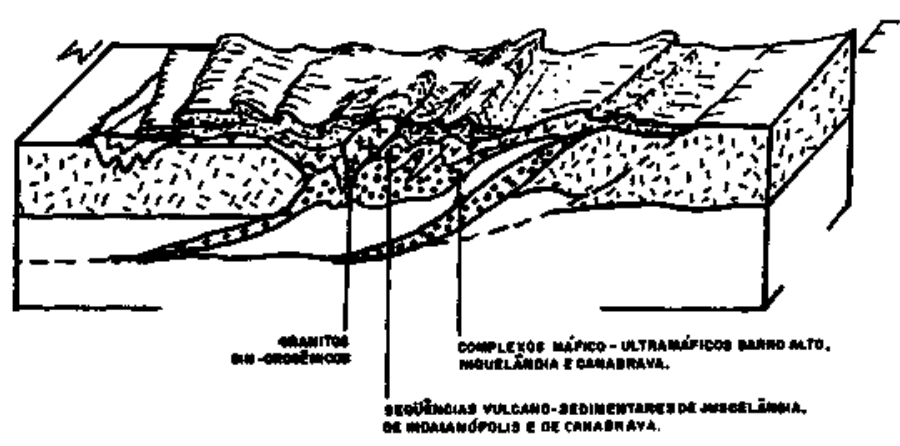

Figura 11 - Modelo geotectônico evolutivo para as Seqüencias de Juscelândia, Indaianópolis e Palmeirópolis Figure 11 - Evolutionary geotectonic model for the Juscelândia, Ihdaianó polis and Palmeiró polis Sequences

Embora os dados geológicos e geoquímicos coligidos nessas regiões apontem para a conclusão enunciada, são necessários estudos mais profundos sobre as rochas meta vulcânicas da Seqüência de Juscelândia (e correlatas) e de suas relações com o Complexo de Barro Alto (e correlates), para esclarecer com maior exatidão a evolução magmática e tectônica ocorrida durante a história geológica do Maciço Mediano de Goiás. 


\section{REFERÊNCIAS BIBLIOGRÁFICAS}

ARAUJO, SM. 1986. Petrologia e Mineralizações Sulfetadas da Seqüência Vulcano-sedimentar de Palmeirópolls, Goiás. Brasília. 196 p. (Dissertação de Mestrado, IG/UnB)

BESWICK, A.E. \& SOUCIE, G. 1978. A correction procedure for metasomatism in an Archaean greenstone belt. Precambrian Research, 6:235-248.

BROD, J A. 1988. Geologia das Rochas Vulcano-sedimentares da Região de Indaianópolis, GO, e lineamentos adjacentes. Brasília. $267 \mathrm{p}$. (Dissertação de Mestrado, IG/UnB)

DANNI, J.C.M. \& KUYUMJIAN, R.M. 1984. A origem dos anfibolitos basais da seqüência vulcano-sedimentar de Juscelândia, Goiás. In: CONOR. BRAS. GEOL., 34. Rio de Janeiro, 1984. Anais... Rio de Janeiro, SBG. v.9, p. 4126-4136.

DANNI, J.C.M. \& LEONARDOS, O.H. 1980. The Niquelândia mafic-ultramafic granulites and gabbro-anortosites metavolcanic associations. Brasilia, IG/UnB. (Inédito).

FUCK, R.A.; DANNI, J.C.M.; WJNGE, M; ANDRADE, G.F; BARREIRA C.F.; LEONARDOS, O.H.; KUYUMJAN, R.M. 1981. Geologia da região de Goianésia. In: SIMP. GEOL. CENTRO-OESTE, 1. Goiânia 1981. Atas... Goiânia, SBG. p. 447-467.

FLOYD, PA \& WINCHESTER, JÁ. 1978. Identification and discrimination of altered and metamorphosed volcanic rocks immobile elements. Chem. Geol, 21(3-4):291-306.

KUYUMJIAN, R.M. 1989. The Geochemistry and Tectonic Significance of Amphibolitesfrom the Chapada Sequence, Central Brazil Londres. 298 p. (Tese de Doutoramento, Imperial College University of London).

KUYUMJIAN, R.M. 199 la. Epidotização e mobilidade de elementos químicos nos metabasaltos de Chapada, Goiás. Geocn. Brasil., (No prelo).

KUYUMJIAN, R.M. 199 Ib. Mobilidade de elementos terras raras em metabasaltos de baixo e alto graus metamórficos. Geoch. Brasil., (No prelo).

MESCHEDE, M. 1986. A method of discriminating between different types of mid-ocean ridge basalts and continental tholeiites with the $\mathrm{Nb}-\mathrm{Zr}-\mathrm{Y}$ diagram. Chem. Geol., 16:207-218.
MYERS, R-E. \& BREITKOPF, I.H. 1989. Basalt geochemistry and tectonic settings: a new approach to relate tectonic and magmatic processes. Uthos, 23:53-62.

PEARCE, J.A. 1982. Trace element characteristics of lavas from destructive plate boundaries. In: THORPE, R.S. ed. Andesites. New York, Wiley \& Sons. p. 525-548.

PEARCE, JA. \& CANN, J.R. 1973. Tectonic setting of basic volcanic rocks determined using trace element analyses. Earth Planet. Sci. Lett. 19:290-300.

SAUNDERS, AJ). \& TARNEY, J. 1979. The geochemistry of basalts from a back-arc spreading centre in the East Scotia. Geochem. Cosmochim. Acta, 43:555-572.

THOMPSON, RJ́; MORRISON, MA; HENDRY, G.L.; PARRY, S.J. 1984 An assessment of the relative roles of crust and mantle in magma genesis: an elemental approach. Phil Transp. R. Soc. London, A310:549-550.

WINCHESTER, JA; PARK, R.G.; HOLLAND, J.G. 1980. The geochemistry of Lewisian semipelitic schists from the Gairloch District, Wester Ross. Scottish Journal Geology, 16:165-179.

WOOD, DA. 1979. The application of Th-Hf-Ta diagram to problems of tectonomagmatic classification and to establishing the nature of crustal contamination of basaltics lavas of the British Tertiary province. Earth Planet. Sci. Lett., 50:11-30.

WOOD, DA.; JORON, J.L.; TREUJL, M. 1979. A reappraisal of the use of trace elements to classify and discriminate between magma series erupted in different tectonic settings. Earth Planet. Sci Lett., 45:326-336.

MANUSCRITO A648

Recebido em 9 de marco de 1990 Revisão do autor em 31 de junho de 1990 Revisão aceita em 14 de agosto de 1991 